\title{
Perspectives of Human Development: Time, Space, and Chrononutrition
}

\author{
D.W. Wilson ${ }^{1, *}$, A.P.S. Hungin ${ }^{1}$, K. Griffiths ${ }^{2}$, R.B. Singh ${ }^{3,4}$, F. De Meester ${ }^{3}$, S. Sanchez de la Pena ${ }^{5, \#,}$ \\ J. Fedacko ${ }^{6}$ and A.Wilczyńska ${ }^{3}$
}

${ }^{I}$ School of Medicine and Health, Wolfson Research Institute, Durham University, UK

${ }^{2}$ Formerly, Professor of Cancer Research, Cardiff University Cardiff, UK

${ }^{3}$ Tsim Tsoum Institute, Krakow, Poland

${ }^{4}$ Teerthanker Mahaveer University, Moradabad, U. P., India

${ }^{5}$ Chronomics Research Center, ENMyH-IPN \& FICRÓN A.C., Mexico

${ }^{6}$ Faculty of Medicine, PJ Safaric University, Kosice, Slovakia

\begin{abstract}
This chapter attempts to step backward in time and space, to consider evolution in the context of chronobiology and chronomics and to then focus on how this science, pioneered by Professor Halberg and his team at the University of Minnesota, can bring improved health benefits to mankind. Although being mindful of this old yet formally modern science, care is taken to include many practical considerations that have a tendency to be sometimes undervalued in research.

Evolution continues under the omnipresence of gravity, changing electromagnetic forces, time, space, and Earth's climate and environment as an ecological biogeographical phenomenon that took place extremely slowly in geological time but is now undergoing change at an extraordinary pace in recent times of human evolution and adaption to their environment [1]. Already about 1 out of 3 billion people go hungry [2] (and currently in overall decline) and by 2050 the estimated population is about 9 billion [3]. Great challenges to reduce poverty and hunger lie ahead: people need to be fed but safely, the risk of inflammatory diseases such as gastrointestinal and cardiovascular disorders needs to be reduced: and one potential area of research concerns chrononutrition. It is by understanding the chronobiological science that underpins health that will enable such goals to be reached.
\end{abstract}

Keywords: Chrononutrition, Perspectives, Human Development.

\section{INTRODUCTION}

It is well recognized that current dietary intakes are generally unbalanced with respect to achieving human health which has probably evolved with the need for high quality, and concomitant high energy expenditure, foods [4] migration, etc., to supply the human's disproportionate relative brain size and function compared to other hominoids [5].

In modern times our applied intelligence has meant more efficient means of harvesting foods for our energy needs through agricultural sciences, cooking, transportation and refrigeration so much so we have become too efficient, overly consuming energy foods beyond our needs.

One such project, the planned Chronomics Project, vide infra, which is an intervention trial aimed at lowering the omega-6/omega-3 ratio in blood and hence tissue, is based

*Address correspondence to this author at the School of Medicine and Health, Wolfson Research Institute, Durham University, UK;

Tel: 44 (0) 19133 40825: Fax 44 (0) 19133 40793;

E-mail: d.w.wilson@durham.ac.uk

Tribute: Professor Franz Halberg, Father of Chronobiology and Chronomics.

"Distinguish chronobiologist and friend. on the notional hunter-gather diet that prevailed during the Palaeolithic time [6,7].

Self-replicating chemical systems in the Hadian eon presumably gave rise to prokaryotes $(c 4 \mathrm{Ga})$ in which RNA was probably 'king', preceding DNA as the genetic material found in eukaryotes [8] $(c 2 \mathrm{Ga})$, evolved through the complex system of endosymbiosis which geochronobiologically [9-11] became ultimately part of the phylogeny of man. There were at least 5 major mass extinctions, en route, caused by falling sea-levels, cosmic events, ocean anoxia, etc. In more recent times, for example, Homo erectus was perhaps annihilated by the Toba catastrophe (youngest of mass extinctions) some 73,000 years ago [12, 13]. Similarly, plants have also developed their own molecular phylogeny (e.g. embryophytes [14] such as that with UV - protective flavonoids which invite i.a. pollination, and biophagy e.g. very latterly humans. It must be recognized that we are part of, and not separate from the environment around us. The Palaeolithic, pre-agricultural, diet of the Homo genus (c2.5Ma) (extant species: sapiens $(c 0.20 \mathrm{Ma}))$ is only partially understood due to limited data [15-18]; but was globally diverse, as man moved further away, from his primate ancestors, to live in Africa, the 
Americas, Europe and Asia, due to i.a. climatic conditions, technological developments, and availability of wild plant and wild animal food sources ( $c f$ chimpanzees [19]; wild land-based food consumption may be beneficial to health [6].

It is probable that the human genome of today, without substantial change [20] existed in Palaeolithic (Pliocene /Pleistocene) times [21]), the major possible differences being the interaction of Nature's environment on gene regulatory mechanisms [22], e.g. gracilization, brain size and function. One possible suggestion, among many, is that the increase in brain size may be due to increased carnivory supplying $50 \%$ of calorific needs [23]. There was increased essential fatty acid consumption such as the brain-abundant $\omega-3$ docosahexaenoic (DHA) and eicosapentaenoic and $\omega-6$ arachidonic acids: DHA is important, i.a. for good mental health. It is easy to speculate on contributory molecular events in human evolution, but supporting data is difficult to obtain, especially on key enzymic adaptive mechanisms for nutrition. However, both DHA and EPA are obtained from $\alpha$-linolenic acids but mammalian conversion is slow [24] and omega- 6 cannot be converted to omega- 3 because there is no $\Delta-4$ desaturase enzyme [25] and their physiological function is distinct and may have opposing action.

Diet has been implicated in health and disease throughout the ages, pre-Christian era in the ancient Ayurveda q.v. 'Sattvic diet to saints' - fruits, vegetables, sprouted grains, roots, nuts, cow milk, curd, honey and 'Rajasic diet to kings and fighters' -fruits, vegetables, nuts, meats from hunted animals, clarified butter, butter, curd, honey, spices, wines; and in ancient scriptures, Bhagwatgita and early Chinese writings [26]. Similarly, advice was given by first century 'physician' Celsus in his epic work De Medicina [27, 28] and Hippocrates before him [28].

It was Halberg et al., [29] who clearly stated that "time structures of key physiological variables are to be mapped in humans and other selected species at different stages of development to examine by means of a comparative physiological approach the extent to which the evolution of the physiologic time structures can lead to testable hypotheses concerning the origins of life". In honour of Professor Halberg's vision we now try to demonstrate the important contribution made by the team at the Halberg Chronobiology Center, University of Minnesota, to the field of nutrition, viz. chrononutrition.

There is abounding scientific literature which details the importance of physiological time structures in health and disease under temporal and spatial environmental conditions: particularly those in man [30] and selected references pertaining to nutrition [31-38]. Consequently, studies of human development necessitate good experiment design. We do, however, evolve in a world which is constantly undergoing temporal and spatial change and chronobiologists, i.a., seek to develop knowledge which can be used to understand biological evolution [39] and which can also be utilized in the service of man e.g. epidemiology [40], child development [41], cardiovascular risk [42]. Through the pioneering work of Halberg and others, clinicians are now very much aware that biological systems have a time structure in which many variables exhibit oscillatory phenomena which includes coordination of biological structures and that such rhythmic processes yield valuable information on human development both in health and disease [43-49] but the question as to how these temporal structures can be identified, quantified and interpreted for gainful use in medicine is often difficult for several reasons; indeed some biological systems, although deterministic in origin, oscillate with no recognizable frequency and the study of such systems constitutes the theory and practice of chaos [50] not to be confused with non-deterministic randomness. We now discuss chronobiology and chronomics in relation to chrononutrition.

\section{CHRONOBIOLOGY AND CHRONOMICS}

Halberg [51] clearly indicated that dietary intervention, for high blood pressure, should take place in utero or at all ages but preferably as soon as possible: substantial intervention being preferable to pharmacological treatment. It is noteworthy that the day-night differences (presumed 'circadian' rhythm) in the cloacal temperature of pigeons observed by Chossat [52] (1843) were still present in the absence of food and under dehydration. Mammalian liver glycogen bioperiodicity was found in histological sections [53, 54], in rodent liver [55] even under circumstances of food deprivation and though substantially diminished [56, 57] was not obliterated. Moreover when data from starved intact animals was expressed as percentage change they were comparable to fed animals [58]. Experiments restricting the amount and timing of food intake demonstrated that mealtime was a synchroniser, based on eosinophil count and the then-indicator for the adrenal cortical cycle $[59,60]$. In humans on a single meal, for example, with mealtimes taken at breakfast or dinner different characteristics in the plasma-high values of insulin and glucagon occur, timings being similar for breakfast and quite separate for dinner. This is not just a case of feeding as the same meal at dinner produces different hormonal responses. Thus the science of chrononutrition was established as documented by Halberg's team [61] and also includes shift schedules which cause internal temporal disorder, which was found to prolong the $10^{\text {th }}$ decile of survival of mice [62]. Further work needs to be done.

Most clinicians and scientists engaged in biological research are familiar with the principles of chronobiology [30] but chronomics, a term introduced by Halberg [63-65] and some of some early work leading to this subject [65-72] extends these principles into a more 'universal' setting. For example, whereas periodicities in the biosphere are the realm of chronobiology, when aligned or integrated with 'weather' on Earth and in space $[65,66]$ they form the basis of chronomics. However, to the uninitiated who attempt such Time Series, Voltaire's "Candide, ou l'Optimisme" springs to mind [73, 74]. Halberg and his team have introduced a set of rules that guides researchers undertaking such work [42, 75].

In Precambrian times $(1 \mathrm{Ga})$ the solar energy alone may have been insufficient [76] (75\% present) to keep the oceans in liquid form but were compensated by increased temperature caused by 'greenhouse' gases existing at the time [77]; although somewhat contentious, the solar cycles may be associated with changing solar energy which 
although relatively very small, may affect weather. Suggestive evidence comes from $11 \mathrm{y}$ cycles of dust measurements from Greenland ice cores [78], that reflect relative aridity, and more recently before and after the 'Little Ice Age' isotope data and human activity [79] reflects possible temperature changes such as on the 'occupational margins'/activities e.g. grape production, whaling, location of burial grounds, economic exports or outputs. The only cycle which was known to exist was the sunspot cycle of Schwabe [80]; q.v. also Hale [81, 82].

Human development, and other life forms that are known to us on Earth, notwithstanding for example, concepts of panspermia [83] or deism [84] (e.g. Averroes), have been spawned following the cosmic dark age [85] by the organization of information over cosmic time from transitional non-ground energy thermodynamic states on Earth 'arising' from the outer corona of the Sun. Although in an expanding space-time continuum one never passes the same point, periodicities abound within it. Cycles are ubiquitous in all living matter (chronobiology) as are those in the environment $e . g$. photic and non-photic of the cosmos which gave rise to the 'footprints' of life itself. Several early studies have shown statistical correlations with human rhythms [65-68]. The resonance of these biospherical cycles with those of the environment constitutes the science of chronomics [86-88]; and rainfall and crops depend on photic and non-photic solar activity.

Hunter [89] has suggested that weather and climate on Earth were influenced by geomagnetic-solar activity and later particularly in the troposphere $[90,91]$ and perhaps more specifically Labitze \& van Loon $[92,93]$ made the possible connection with the 11-year solar cycle as did FriisChristensen \& Lassen [94]. The work by Grafe \& Heider [95] has suggested a 6-y delay in global temperature compared with geomagnetic activity which may, along with local geographic factors, allow some planning in agriculture production strategy that will be needed especially if the projected estimates of the FAO of 9 billion people requiring nutrition is correct. However, "magic bullets must have magic guns" [96], and so the major implementation of systems are needed for nutrition and disease control. Meanwhile, the work of Halberg continues to develop chronomics, not only in chrononutrition, but also in other areas of concern about human health such as cardiovascular disease.

\section{Time}

Chronobiology considers both cosmic (day, night, week, month, year, etc.) and organismic time in a biological sense is concerned with rate processes at a neural, humoral, cellular, metabolic, etc. level. However, it is the temporal, spatial and biological integration arising from solar and terrestrial processes that epitomizes chronomics as a scientific discipline. Real time concerns the influence of cosmic and biological time which, in genetically programmed human development, occurs as life embarks on a sequence of events from conception, birth, onset of puberty, reproduction, 'ageing' and death [97, 98]. It is the influence of real-time changes in the organism that controls health, work efficiency, moods, psychomotor skills, and other activities. However, these real time processes take place under the influences of cosmic, biological and social space which are complex entities.

\section{Solar-space and Environment}

Cosmic space in the vicinity of the Sun is neither isotropic nor homogeneous and space weather comprising corpuscular highly energetic particles (solar wind) interact with the terrestrial magnetic field. Of relevance to cosmic space is the presence of photic and non-photic radiation. Photic radiation is well documented in the biological literature but non-photic magnetic radiation is extremely intense in the vicinity of sunspots $(c 0.3 \mathrm{~T})$ [99]. Solar processes bring gigantic (and smaller ones) magnetic fields to the Sun's 'surface (a misnomer as there is no definitive disc)' and, breaking through the photosphere, have a major impact on the activity of the chromosphere and hence space weather. Possible splicing and re-splicing of these magnetic fields is possibly demonstrated by sun-spot cycles $(c 11 \mathrm{y})$ which are areas of cooler regions of high magnetic intensity which migrate along the Sun's 'surface' due to the differential latitude-dependent solar rotation ( $c 27 \mathrm{~d}$ (equator)$32 \mathrm{~d}$ (poles)). The resulting inter-planetary magnetic field vector $\left(10^{-4} \mathrm{~T}\right.$ near the Sun's surface; $c 10^{-6} \mathrm{~T}$ near-Earth) interacts with terrestrial magnetic field and it is the $B_{Z}$ component which can oppose (protect against ionized particles) or re-enforce each other and hence possibly adversely influence the biosphere (possibly magnetotactic bacteria) and human development (T. Kino (2009): Personal communication: a family, sensitive to magnetic fields, was found to contain Fe containing protein, viz. cryptochrome CRY 1 \& 2. This possibly implicates the effect of environmental electromagnetic fields on humans; q.v. geomagnetic disturbances are associated with reduced nocturnal excretion of a melatonin metabolite in humans [100]. Such possible effects are anticipated in Polar Regions (Aurora, goddess of dawn: siblings, Sol/Luna; children, Anemoi (Winds)) and where their effect on biological life may be more prevalent in high-density populated northern latitudes. It is true to say that biological life develops in a changing cosmic space-time environment which may extend to intra- and extra-galactic phenomena. For the moment we focus on how the blushing ballerina's magnetic skirt [101] reveals dangers to human health that may also be influenced by stellar and lunar activity.

\section{Terrestrial Space and Environment}

Terrestrial space is concerned with 3-dimensional space represented by polar co-ordinates describing altitude, latitude, longitude and other dimensional properties of a near-spherical planet. Within this environmental space, light, heat, radioactivity, magnetism, water, chemical substrates, etc. have forged biotypes, biosystems, and such integrations, biocenoses, became metamorphosed and have formed communities, often located on a sensitive precariouslybalanced 'mobile' governing life on this planet, some being symbiotic and others hazardous or destructive. Mankind has created sprawling cities and so distinctions have to be made concerning urban, rural, and other spaces wherein environmental pollution, occupational and social facets of time impose their societal signatures upon health and disease [102]. For example, based perhaps on similar lifetime 
experiences of their environment, ceteris paribus, including chrononutrition, some develop mental illness, others physical problems and others are seemingly unaffected. This may be the case, or otherwise, with such illnesses as gastrointestinal disorders (e.g. Irritable Bowel Syndrome) where symptoms are manifested but there is no discernible pathology. Mind-body interactions are discussed later (vide infra). Chronomics has to recognize many of these time-space definitions when evaluating, for example, human development in health and disease. Two more types of space need to be defined, viz. cultural and body space.

\section{Cultural Space and Environment}

Cultural (and inter-cultural) space is a vast subject with its overlapping, emotional, religious, occupational, criminal, communication, and recreational geographies, discussions of which are outside the scope of this paper. However, of speculative relevance to cultural space (and time) are memes [103]; mind-mind replicators, and even temes [104] (technological - mind transfers) which perhaps are the next generation(s) of replicated mechanisms for information transfer from the biosphere to the noosphere [105], the first major mechanism developed in life forms being genes. We pursue the Halberg philosophy [106] to "measure in time what is measurable and render measurable what as yet is not": otherwise such speculation may be premature and scientifically uncertain. Uneasily chronomics may be exploring the evolution of a single-brain embryonic planetary structure $[107,108]$ (with reservations) comprising living breathing cities with inter-connecting data highways planning its own survival.

\section{Biological Space and Environment}

Biological space has been well-documented under the guise of chemical and compartmental/anatomical pools [109, 110] wherein a pool ideally is an amount of material which behaves kinetically like a distinct homogenous entity. Anatomical pools may include organs, tissue, urine, blood, plasma, saliva, seminal plasma, cerebrospinal fluid, milk, nipple aspirate, amniotic fluid, or stores of chemicals in individual organs or organelles, etc., and interconvertible chemical pools could include for example, androstenedione and testosterone. Given an appropriate anatomical space (e.g. plasma pool) and a variable (e.g. hormone) have both been identified, various mechanisms may apply such as feed forward (energy reserves), feed back (hypothalamic - pituitary and hormone networks) and feed sidewards where resources are changed arising from metabolic or time-dependent processes or even another anatomical pool [111]. Another example may be solar weather which rarely acts on one variable in an interacting biological system; it constitutes multifrequency components of electromagnetic radiation and so is expected to exhibit feedsidewards phenomenon [112] in individuals.

Current research in chronomics also seeks to explore mind-body interactions that may shed light on many medical problems such as gastro-oesophageal reflux disease. The diagnosis and treatment of Irritable Bowel Syndrome could be improved if these body-mind interactions could be explained in terms of disease severity and associated pain; thereby complementing the Rome Criteria [113]. Tools for such investigations include fMRI scanning which is used to identify areas of the cerebral cortex which respond to painful stimulation Particular attention focussed on chronobiological and dietary aspects of this disease and the quest for biological markers, possibly via intra- and extra- pineal melatonin networks [114, 115], may aid diagnosis and treatment.

\section{CHRONOBIOLOGY AND SAMPLING ISSUES.}

\section{General}

Halberg has made substantial contributions concerning quality assurance (e.g. clinical endocrinology [116]). Today many clinical and epidemiology studies utilize timeunqualified analytical and physiological measurements as covariate indicators of co-morbidities and in many ways are perhaps doomed to failure. Halberg has pioneered better therapeutic approaches that capitalise upon chronotolerance and chronoefficacy (and challenges of the concept of clinical equipoise $[117,118]$ are necessary), but better still, he has focussed on disease prevention and potential intervention approaches through chronobiological health monitoring. An ounce of prevention is worth a pound of cure, once said Professor Tarquini [119]. Fundamental to any study of human development, such as nutrition, are that measurements from any pool must have the ability to measure what is purported to be the analyte under consideration.

For new analytes of interest it is necessary to strive for reference methods for their validation otherwise their value will be suspect [120]. Thus the analytical method is a written set of instructions for a specific purpose that involve the analyst, the reagents, the apparatus, and all steps and procedures, computational and statistical that lead to the result. Thus methodological accuracy and precision are fundamental properties of an analytical system, associated with which are specificity, sensitivity, and in-control quality assurance over analytical time [121].

Difficulties often arise where there is no available gold standard e.g. mass spectrometry against which to judge the accuracy of the method, even this has precision implication limitations. In all most chronomic studies it is preferable to have statements on accuracy relative to a reference method, analytical precision expressed as a precision profile, limitations of the assay working range with its definition, estimate of detection limit [122, 123], the nature of the sample being analysed, details of intra- and inter-assay variability and quality control criteria used to monitor analytical performance over time [120], robustness characteristics, tolerance charts ( and the basis of outlier rejection and design considerations as to how the samples were arranged (in blocks) and submitted for assay; vigilance about matrix and gender effects should be exercised. Of course, not all diagnostic tests require such rigour (e.g. IL8) - elevated concentrations may suffice). Now chronobiology constructs time-space reference intervals building [124] on from Claude Barnard (q.v. Foster [125] \& Halberg [126, 127]) with definitions for health (Halberg [128]; contrast WHO [129]) using routine methods e.g. immunoassay and liquid chromatography and tandem mass spectrometry to produce prediction and tolerance charts, viz. chronodesms.

Urinary metabolites, when assayed, are generally quite difficult to interpret and perhaps should be looked at as a 
networking repository prior to excretion whereupon many hormones, ions, and organs, exert influence [130]. The adrenal gland has an important role in human development. Although much has been achieved such as the (non-time qualified sample of circadian) declining concentration of 11deoxy- 17-oxosteroids with age [131], it was Bartter [132] and Halberg et al., [133] who added the circadian time dimension but even so the metabolic milieu is complex [134] and difficulties have been expressed on the duration of sampling to obtain minimum variability [135], now understandably.

Plasma is another body pool which comprises about $90 \%$ water and protein binding entities which are additional chemical pools for some hormones and delivers excretory, metabolic and endocrine products to their end organs. Other pools such as erythrocytes, platelets and leucocytes are suspended in plasma, and plasma contains a myriad of physiological biochemicals, ions, and so forth. Similar principles apply to sampling and assay of analytes, so very important in nutrition, but further discussion is beyond the scope of this report.

It is saliva which potentially offers the chronobiologist and nutritionist scope for chrononutrition following the seminal paper by Colin Dawes in 1975 [136] and this 'space' will be discussed in detail with regards mainly to steroids and melatonin.

\section{a) Salivary Steroids}

Expressed simply the main salivary exocrine encapsulated gland - pairs in humans are the sublingual, submandibular and parotid glands (and some buccal glands) connected to nerves and blood vessels via hila [137]. It is the glandular secretions, generally containing enzymes to aid digestion, which also contain substances that may reflect blood/plasma concentrations or indeed be synthesised in situ [138]. The general mechanisms for transport from the blood borne ligands are assumed but also supported by experimental evidence [139]. The mechanism of steroid transport from the plasma/blood pool to the capillary cells and thence to the salivary gland apparatus and saliva may involve active transport, passive diffusion, ultrafiltration which may be complex depending on whether the steroid is neutral. Research has shown that, for example, concentrations of some neutral steroids (e.g. cortisol, progesterone, and $17 \alpha-\mathrm{OH}$ progesterone) analysed by immunometric assay (sensitivity c1-4 pg: validated by selected ion gas chromatography-mass spectroscopy) in whole saliva were 'identical' to those in parotid fluid under stimulated conditions, and matched saliva with plasma collected approximately mirrored each other in profile but concentrations were different [140]. These relationships persisted over circadian and circatrigintan timespans and furthermore for these steroids the whole saliva values appear to be in accord with the non-protein bound moiety found in plasma, similarly testosterone (sensitivity was $4 \mathrm{pg} / \mathrm{tube}$ [141]). Dehydroepiandrosterone sulphate does not seemingly reflect the free plasma steroid [142, 143], its concentration being lower. Care must be taken over oral micro-injury or gingival crevicular contamination, or even from food products and saliva stimulants for neutral steroids should be avoided because of recovery issues [144]. Storage of saliva samples (plastic $5 \mathrm{ml}$ tubes and stoppers housed in a polythene holder) for cortisol and testosterone assay has been remarkably stable in snowfields of Spitsbergen and Greenland [145] at $-20^{\circ} \mathrm{C}$ for many months or longer; generally stable for several days in the domestic refrigerator at $4^{\circ} \mathrm{C}$ prior to storage at $-20^{\circ}$ as confirmed by quality control samples stored in an identical way as study samples.

For applications of saliva as a suitable medium, for example, in chrono-epidemiological studies, it is generally concluded that for selected analytes, subject to collection criteria [146, 147], that saliva has many advantages [148]. For example, it is 'stress'-free, purportedly represents the non-protein bound analyte found in plasma, enabling multiple non-invasive samples, easily collected in a wide number of recreational, occupational, clinical, environmental, and military situations. Though saliva assays are not without problems of storage, matrix effects, metabolism and assay specificity and sensitivity. For example, incubation studies with so-called healthy parotid and submandibular tissue with labelled $\mathrm{P}$ and $\mathrm{T}$, have demonstrated conversion to the 20 alpha-hydroxy-4-ene-3one and androstenedione respectively, the submandiular tissue being more active. Due to rapid transference of these hormones from blood, this degree of metabolism is not expected to significantly affect saliva concentration arising from circulation [149]. There is also evidence, for example, that DHEAS (in the context of steroidsdehydroepiandrosterone sulphate) may have its own intracrine mechanisms (steroid sulphatase activity) as demonstrated by real-time PCR [143] which is different between healthy adult controls and in those with Sjogren's syndrome with the latter having lower DHEA and androgen concentrations. Gallagher et al., [150] showed that DHEA in only unstimulated saliva correlated with plasma values and this is the recommended method [150].

The chronomics of human development embraces the space-time-environment hitherto described in healthy and sick individuals. Ahn et al., [148] carried out a restricted circadian study of salivary cortisol and DHEA in 36 adult male and 40 female Koreans aged 20-40y, but cortisol did not change significantly with age and neither did DHEA until c40s onward. This study, albeit commendable, can be advanced to take cognizance of seasonal, circaseptan and other temporal structures.

Studies of the human chronome as it relates to human development (and chrononutrition) when expressed extends from conception whence maternal-foetal exposure to hormones possibly gives rise to low testosterone before birth and high oestradiol at puberty and gene activation may lead to disorders in eating. These events may influence, in children and young adults, the possible onset of premetabolic disease, hypertension, and affect spatial cognition, measures of intelligence, and other psychobiological developments. However, the development of the conceptus, through its embryonic and fetal stages, is influenced by exposure to maternal/fetal/placental network and amniotic fluid environments, including oestrogens, androgens and nutritional factors. For example, maternal oestrogen, including phyto-oestrogens from the diet which may facilitate gene imprinting in utero or in the neonate leading to possible hypermethylation of DNA which may predispose 
the child to increased risk of some diseases later in life [151, 152]. Too few studies have focussed on the chronomic multisampling approach but instead rely, inter alia, on sparse data to develop hypotheses on the interactions of the chronome with the environment, albeit in humans neonatally and thereafter.

Saliva, as a medium, has enabled neonatal circasemidian rhythms of cortisol in $48 \mathrm{~h}$ newborns to be identified with no apparent influence on their state of arousal, light/dark and feeding schedules, time of day or time of birth [153]. In the same study, circadian rhythms were identified in the 3-5y old and the adult. Sexual dimorphism brought about within the human chronome and ensuing regulatory processes, especially hormones or substances of dietary origin, underpin development in numerous areas, for example, lung function, gastrointestinal tract and brain function involving neural processes and signalling mechanisms elsewhere, including possibly in the gastrointestinal tract where nutrition begins with ingestion of amniotic fluid and nutritional sources at and following neonatal development. Amniotic fluid testosterone, perhaps indicative of exposure, may affect cognitive skills such as spatial tasks. Thus the chronomics of salivary testosterone e.g. 1-6 month surge may provide insight into autism, maleness in opposite-sexed twins, and other psychological, psychosexual and psychosocial behaviours. Early studies have demonstrated the utility of salivary testosterone in the development of puberty in boys with elaborating circadian time structures e.g. from low to high circadian amplitudes and Mesors comparable with the young adult male. In cultural, genetic and cosmic space in differing environments, saliva has been found to be useful [154-156].

Potentially exciting and rewarding areas of interest using saliva assays for assessing disease risk in both males and females may be nutritional, exercise and genetic factors undertaken using cross-sectional and longitudinal studies of Parsees, Sikhs, Bangladeshis, Hutterites, Mormons, Icelanders and other populations where gene pools have less variation. Moderate levels of acute or chronic anxiety, psychosocial stress do not seem to affect ovarian function as assessed by daily synoptic samples of salivary oestradiol and progesterone; similarly cortisol in well nourished Western women. Nunez-de la Mora, vide supra, looked at environmental issues, perhaps impacting on the immune system, and generated oestradiol and progesterone profiles, in first and second generation Bangladeshi migrants living in London. These were compared with those of European descent living in similar neighbourhoods in London, and Bangladeshi women in Sylhet and interpreted their findings such that women, prior to reproductive maturation, monitor their environment and programme their ovarian function in accordance with expectations.

It has been reported that daily samples of saliva for progesterone assay in menstruating females 18-44y approximated the observed fecundity with chronological age [157]. Comparison of salivary steroid profiles in terms of human development, necessitates congnisance of time and space and environment (e.g. dietary phyto-oestrogens [158]).

Additionally, studies of communities may lead to some individuals having brain function that responds differently to hormonal changes in puberty resulting in eating disorders and other health risks.

\section{b) Melatonin}

Mammalian melatonin, synthesised by the pinealocytes in the pineal gland, the gastrointestinal tract, skin, iris, lens, and elsewhere, has been assayed in saliva. Circadian rhythms of melatonin, under the influence of non-image forming light via connecting axons of photosensitive retinal ganglion melanopsin-bearing cells within the retinohypophysial tract to the suprachiasmatic nuclei (clock gene (per1-3, Cry1-2) network) and thence to pineal where melatonin is synthesised and secreted generates neural and endocrine signals to co-ordinate circadian and other rhythmic structures (e.g. seasonal [159]). Melatonin has an antioxidant role. Thus chronomics has a role to play in the initiation and development of various diseases in cultures at different latitudes (melatonin adaption to shift working times in Thai female shift workers [160]), and in industrialized (and developing) countries where lighting and occupational patterns of activity have been/are important health factors. Melatonin has been assayed using deuterated internal standards in high-pressure liquid chromatography tandem mass-spectroscopy [161].

Salivary peak melatonin and circadian rhythms are not changed by 2-night rotating shift workers (nurses): therefore sleep not a proxy for melatonin [162] but timing of dietary input and constituents may be important and a longer sampling study may reveal otherwise. However in patients with Delayed Sleep Phase Syndrome, the onset of salivary melatonin, adjudged by a dim light onset test, was also delayed. Chrononutrition will almost certainly be important on changing temporal and constituent patterns of dietary intake and melatonin may be one determinant of subjective well-being [163].

Neonates have very similar results of salivary melatonin cf serum [164]. Children with idiopathic sleep-onset insomnia have an advanced sleep-wake cycle on treatment with melatonin which improves their clinical condition. It is possible that the aetiology of functional gastrointestinal disorders may have a chrononutritional melatonin component [165] and so it would be interesting to investigate the incidence of Irritable Bowel Syndrome in the blind [166]. Decline in melatonin and changing circadian characteristics (in Chinese) starts to take place in middle age and declines thereafter [167]. Elderly subjects, however, often have hyposalivation and lower concentrations in plasma which may limit the analytical method in terms of its operational characteristics. An important aspect of nutrition is the dietary component of melatonin which possibly exerts influences in concert with pineal melatonin. Therefore dietary melatonin may have roles where traditional clinical sleep related dysfunction have been investigated. It is Halberg's group that has demonstrated circadian rhythms in a local geomagnetic activity index in Alta the peak of which precedes that of melatonin, though statistical associations are not necessarily causal [115].

The limitations of using saliva for studying civilization diseases that implicate a wide range of dietary components have been reviewed using steroids and melatonin as examples. These authors suggest that dedicated laboratories 
are needed for chrononutrition studies and of biomarkers in civilization diseases capable of developing and evaluating assays and/or kits, designed to evaluate endocrinological networks with respect to analytical performance characteristics of saliva assays such as reference standards e.g. sampling and analytical procedure (specific for purpose), mass spectrometry, storage stability, batch-sample design, sensitivity, inter- and intra-assay variation, working range, precision profiles (standards and samples), process control, and statistical analysis and related issues.

Plants, too, have their pools and compartments and it is useful under environmental conditions to temporally understand and predict the movement of nutrients from soil, water and aeolian sources as part of chrononutrition. For example, acid rain, dust, radioactivity such as the Chernobyl and Fukushima disasters, presumably emanating isotopes of lead, caesium and strontium, fall on leaves the function of which is to regulate carbon dioxide exchange and water loss through stomata. The greater part of the surface is covered in a waxy cuticle through which non-polar compounds can move.

The surface of the leaf is coated with a waxy cuticle (http://mdc.mo.gov/discover-nature/habitats/forests/structureleaf last accessed 25th June 2011) but openings exist within the epidermis, viz. stomata, through which moisture (and carbon dioxide) can flow. The flow of material is controlled via guard cells but the mechanism of control is not fully known. Stomata densities may vary with annual rainfall, may differ on upper or lower side of leaf, and exhibit circadian change, and other environmental conditions [168]; even stomal apertures in different areas of the same leaf may vary according to microclimatic conditions [169]. Sudden prolonged darkness, leaf temperatures in excess of 30 degrees Celsius, high winds and dry soil cause stomatal closing: low wind speed, lower temperatures and wet soil lead to stomatal opening.

In its simplest form, the 'wettability' of the leaf surface by rainfall can be described by a gas (air)-liquid-solid interface system which at equilibrium must have forces, at each interface, that balance. Different plants have their own characteristics, e.g. hydrophobic surfaces of cabbage leaves make wetting difficult to achieve. However, solutes in solution have an impact on 'wettablity' and transference; if solutes decrease the surface tension then they are surface active; if they increase the surface tension e.g. electrolytes, then their concentration at the interface will be less than that for the internal droplet concentration resulting in so-called negative adsorption. The presence of charged surfaces, particulate carriers of radionuclides are likely to exert an effect on nuclide sorption into the plant and their structures (vide infra).

The surface properties of the leaves, especially epicuticular waxes, affect 'wettability', but microstructures including hairs and other features of the surface of the leaves may also be influential. 'Wettability' results in part from the need for leaf waxes to conserve leaf (internal) water, but it also permits the removal of surface deposits. Barthlott and Neinhuis [170] studied surface properties of several species and demonstrated experimentally that particulate contaminants, applied as dry deposits in the size range 0.5 to $30 \mu \mathrm{m}$, were removed by artificial rainwater applications to the more water repellent leaves. This effect was named the 'self cleaning' or 'Lotus effect' as the leaves of this species (Nelumbo nucifera) were the most water-repellent of those studied. Presumably this confers the advantage to the plant of removing pathogenic fungal spores. This short section serves only to illustrate that even the accessibility of fruit compartments via leaves is a complicated process but so important when deciding whether fruit and other edible plants are safe to eat under seasonal and associated climatic conditions and their chronobiological structures e.g. growth. Pool sizes of plants and indeed their tissue content, so important in many areas such as fermentation products, and their general signalling processes are discussed no further; similarly signalling processes in endocrinology [171] and human tissue pools.

Thus far, this report has focussed on human development from a chronobiological/ chronomics viewpoint emphasising the need to understand the broader aspects of nutrition. Biomarkers for civilization diseases are multifarious. Fundamental to understanding the initiation, detection, development and intervention of many diseases such as cardiovascular disease is a knowledge of human development (immunological challenge, diet (energy) and nutrition, exercise), adjudged from hypothalamic-pituitary-end organ networks in 'real time and space' wherein saliva is often a convenient non-invasive medium from which to frequently sample endocrine-related outcomes relating to ovary, testis, adrenal, pineal gland, adipose tissue, gastroenterological tract, etc. for males and females. Gene imprinting by transplacental transmission of an oestrogen signal may result in certain genes not being encoded or expressed, leading to dysfunctional growth later in life. In males this dysfunctional growth may be manifest in proliferative inflammatory atrophy which may be a forerunner of preneoplasia, prostatic intraepithelial neoplasia or cancer.

\section{Aspects of Dietary Intervention}

Reports in the literature suggest dietary changes for reduced cardiovascular disease (CVD) which includes reduced percentage of calories from fat, reduction in the amount and timing of food intake change from saturated animal to unsaturated vegetable fats rich in omega-3 fatty acids and to eat plenty of fruit, vegetables and nuts. Indeed, feeding omega-3 fatty acids to chickens produce omega-3rich eggs which are aimed at reducing CVD. A broad-brush description of key dietary components is that soyabean proteins have a beneficial effect on coronary arteries, but soyabean also produces isoflavonoids; fruits produce flavonoids, vegetables have carotenoids, and cabbage/ onions/ chives/garlic-allins, and walnuts/berries/ grapes/ peanuts have polyphenol compounds. Many of these compounds (e.g. phyto-oestrogens), besides contributing to a healthy diet for CVD risk also exert an influence leading to decreased cancer risk, e.g. green-yellow vegetable soup possibly reduces lung, breast and prostate cancers [172]. Phyto-oetrogens have antagonistic and antagonistic oestrogenic properties.

There is a considerable weight of evidence that would suggest that diet, and implicitly aspects of nutrition, has a major influence on carcinogenesis, e.g. breast, prostate and colorectal cancer $[173,174]$, but controversy abounds. It 
would seem from migrant and other geographic epidemiological studies that supplementation of the diet with certain Eastern foods is beneficial and cardioprotective.

However, there is an enormous amount of work to be done. Just as humans exhibit systematic changes depending on geographical location [175] and (conditions) so too do plants consumed in our diet. The pharmacology industry expends considerable effort in ensuring the active chemical conforms to standards of chemical purity, mass and similarly the 'inert' matrix that delivers it; notwithstanding that it may be delivered using an inappropriate time schedule [176] to elicit optimization between chronoefficacy and chronotolerance. Agricultural products do not lend themselves to such rigour. Indeed it was Hippocrates who said "Whoever gives these things no consideration and is ignorant of them, how can he understand the disease of man?". Take for example some basic products which contain antioxidants and which may inhibit carcinogenesis or is cardioprotective. Three examples on polyphenolic flavonoids, viz. strawberries, tea and garlic, serve to illustrate the food production related problems that an epidemiologist may/should face in attempting to derive evidence-based information that demonstrate a particular health promoting dietary component.

Taking the seemingly simple case of strawberries [177] high in lignans, secoisolariciresinol and enterolactone and have among known fruits one of the highest anti-oxidant activity but this is dependent on cultivars [178] or genotype [179]. The human is often driven by flavour which arises from the interaction of volatile and non-volatile components $[180,181]$ which includes more than 200 compounds such as esters, etc. and non-volatile components such as soluble sugars e.g. glucose, fructose and organic acids e.g. citric and malic acid, tannins (polyphenols) that cause astringency by binding salivary protein causing aggregation. There is substantial pick-to-pick (possibly stage of maturity), fruit-tofruit and shading; but metabolism is not suspended on storage [182]; however flavonols remained similar on storage. Understanding variation in metabolic processes is complex but since metabolism is dependent on light and carbon dioxide for photosynthesis then shading is likely to alter plant syntheses and some of the enzymes in pathways are becoming apparent [183]. Many aspects of plant production are not discussed, such as isoflavone glycoside preferential leaching on cooking [184], season, soil and climatic conditions prevailing at different stages of plant development.

Tea, in folklore discovered by the father of folklore Emperor Shan Nong (2737 BC) has been implicated in beneficial anti-oxidant [(Green tea [185] - (3 - gallate derivatives of (-) epicatechin and (-) epiallocatechin)) and anti-carcinogenic properties, such as lung cancer [186] (diallyl sulphide)]. However, tea (Camellia sinensis) is a complicated product with perhaps thousands of varieties all with their individual properties intended for human consumption. Soils, elevation, climate, etc. will determine flavour and inherently chemical composition. Picking factors, such as size - flower pekoe (buds), orange pekoe (young leaves) and souchong (old leaves) - the orange pekoe may have several flushes. They are processed and give rise to green, black and oolong teas. Green tea is tea which is steam heated to inhibit fermenting enzymes and then rolled and heated for packaging. Black tea (containing quercetin [185] is tea which is allowed to be left to partially desiccate, then rolled to break cell structures and to release enzymes that facilitate fermentation, reaching an approved flavour and colour. The tea is heated and packaged. Paraphrased, oolong tea is intermediate in colour and flavour and processing to that of green and black tea. One important aspect of tea is that it is an aqueous extract which is consumed and thus more easily amenable to analysis of principal dietary constituents which may have health promoting, or otherwise, properties.

Documented in the Codex Ebers, Ayurvedic medicine (Charaka), and expounded by Hippocrates and Pliny the Elder, garlic has been recommended for a healthy heart. Modern-day medicine has isolated alliin, an organosulphur compound which reportedly inhibits carcinogenesis [187] and an analogue, alliin, inhibits platelet aggregation [188]. In similar fashion, the constituents of garlic depend on soil, season and climate prompting research into potential analogues, precursors or metabolites that might lead to improved treatments through chrononutrition.

The aforementioned examples do not mention artificial colourants, spices, cooking artefacts and pollution. On the later point half of the people world-wide use solid fuels of one sort or another in cooking that leads to risk of lung disease, and cardiovascular diseases. However, the technology is available for the building of databases for a number of plant products that could bring health benefits, either as dietary supplements or leading to new drug development. These now exist in many countries e.g. Helsinki [189] and Holland [190]. However, unless a miracle drug like aspirin is found then we have to focus on human tissue instead as being the vanguard for certain diseases, possibly cardiovascular disease.

Omega-3 fatty acids rich foods and physical activity are important advancements in the prevention and treatment of coronary heart disease. However, these treatment modalities are not effectively applied because physicians have limited knowledge about chronotherapy and circadian occurrence of cardiovascular events, indicating the need for newer strategies for prevention. This challenge is being met with the establishment of Tsim Tsoum Institute at Krakow in Poland. The Tsim Tsoum Concept is an extension of the Columbus Concept. While Columbus Concept is a 1-D approach that establishes the basis for the "essential" components of the diet, Tsim Tsoum is a 2-D approach that focuses on the "functional" components of the lifestyle: functional foods, positive stress, physical training, meditation. Chronobiology is an important aspect of this approach, because it is based on mind-body interactions which could be modulated by dietary choices, physical \& mental activity, meditation, and the like, all leading to human development (http://www.tsimtsoum.net/introduction_07.php). Details of the TsimTsoum Concept can be obtained from the authors. The 2008-2013 Action Plan for the Global Strategy for the Prevention and Control of NCDs was developed by WHO. Evidence shows that the NCD burden on lives and economy can be decreased by appropriate integrated approaches to health policies applied to: individual risk reduction, population risk reduction, rational use of health services, and 
referral system support and help from non-government organizations. Consequently, these authors believe that chrononutrition will assist in the fight against 'overnutrition' and inflammatory diseases which are reaching a staggering global prevalence.

\section{SUMMARY}

This chapter has illustrated the scientific principles in human development in time and space in which chrononutrition has a pivotal role. It has not been the purpose to discuss nutrition in traditional settings rather to open up horizons for improved Western-Eastern medicine which is one of the plinths upon which the Tsim Tsoum Initiative is based. Moreover, it has given the authors the opportunity to reflect on some real experiences the authors are privileged to have had, and continue to have, with Professor Franz Halberg in his $93^{\text {rd }}$ year as he has developed his chronobiology and chronomic visions into a truly remarkable discipline. This has been just one of several opportunities that the authors have had under the banner of human development and chrononutrition. Several of the authors have worked with Franz for decades, and there have been many times when 'keeping up' with his scientific visions have been extremely challenging: he often seemed to have seven-league boots. When thinking of bygone marvels (albeit not yet) one may contemplate the seven wonders of the Ancient World, particularly the Colossus of Rhodes [191], a giant figure, representing Helios, the personification of the Sun, also represented by a sonnet by Emma Lazarus on a plaque on the Statue of Liberty. Taking the fanciful depiction of this ancient wonder astride the harbour channel, we think of chronomics, the Earth and the Cosmos and the great contributions Professor Halberg continues to make in this once-fledgling science.

\section{CONFLICT OF INTEREST}

Declared none

\section{ACKNOWLEDGEMENTS}

Support by the Wolfson Research Institute and the Tsim Tsoum Institute is acknowledged. Suzanne Sanders, School of Medicine and Health, Durham University, gave secretarial assistance in the preparation of this manuscript. Any shortcomings are due to DWW (Mea culpa).

\section{REFERENCES}

[1] Skelton P. Evolution: a biological and palaeontological approach, Wokingham. England: Addison-Wesley Publishing Company, 1993.

[2] Anon. Undernourishment in 2010, by region (millions). Available at: http:// www.fao.org/hunger/hunger-graphics/en/ [Accessed June $\left.25^{\text {th }} 2011,2010\right]$.

[3] Anon. World summit on food security. Feeding the World, eradicating hunger. WSFS 2009/INF/2. Rome, FAO 2009.

[4] Leonard WR, Robertson ML, Snodgrass JJ, Kuzawa CW. Metabolic correlates of hominid brain evolution. Comp Biochem Physiol A 2003; 135: 5-15.

[5] Stanford C, Allen JS, Anton SC, Lovell NC. Biological Anthropology: the natural history of humankind. Toronto: Pearson Canada 2009

[6] De Meester F. Wild-type land based foods in health promotion and disease prevention: the LDL-CC:HDL-CC model. In: De Meester F, Watson RR, Eds. Wild type foods in health promotion and disease prevention. NJ: Humana Press 2008; pp. 3-20.
[7] Singh RB, Moshiri M, De Meester F, Juneja L, Muthusamy V, Manoharan S. The evolution of low w-6/w-3 ratio dietary pattern and risk of cardiovascular diseases and diabetes. J Altern Med Res 2011; 3 (in press).

[8] Halberg F, Barnum CP, Silber RH, Bittner JJ. 24-hour rhythms at several levels of integration in mice on different lighting regimens. Proc Soc Exp Biol (NY) 1958; 97: 897-900.

[9] Wells JW. Coral growth and geochronometry. Nature 1963; 197: 948-50.

[10] Margulis L. Symbiosis in cell evolution. Basingstoke, UK: W.H. Freeman and Co. 1981.

[11] Hughes WW. Planetary rotation and invertebrate skeletal patterns: Prospects for extant taxa. Surv. Geophys 2005; 7(2): 169-83.

[12] Ninkovich D, Shackleton NJ, Abdel-Monem AA, Obradovich JA. Izett G. K-Ar age of the late Pleistocene eruption of Toba, North Sumatra. Nature 1978; 276: 574-7.

[13] Gathorne-Hardya FJ, Harcourt-Smith WEH. The super-eruption of Toba, did it cause a human bottleneck? J Hum Evol 2003; 45: 227-30.

[14] Raven JA. Land plant biochemistry. Philos Trans R Soc Lond B 2000; 355: 833-46.

[15] Lee RB. What hunters do for a living, or, how to make out on scarce resources. In: Lee RB, DeVore L, Eds. Man the hunter. Chicago, IL: Aldine de Gruyter 1968; pp. 30-48.

[16] Eaton SB, Eaton SB III, Sinclair AJ, Cordain I, Mann NJ. Dietary intake of long chain polyunsaturated fatty acids during the Palaeolithic period. In: Simopoulos AP, Ed. The return of w-3 fatty acids in the food supply. Land based Animal Food Products and their Health effects. World Rev Nutr Diet 1998; 83: 12-23.

[17] Eaton B. Evolution and cholesterol. World Rev Nutr Diet 2009; 100: 46-54.

[18] Singh RB, Reddy KK, Fedacko J, De Meester F, Wilczynska A, Wilson DW. Ancient Concepts of Nutrition and the Diet in Huntergatherers. Open Nutr J 2011; 4; 130-5.

[19] Stanford CB, Wallis J, Matama H, Goodall J. Patterns of predation by chimpanzees on red colobus monkeys in Gombe National Park, 1982-1991. Am J Phys Anthropol 1994; 94(2): 213-28.

[20] Cann RL, Stoneking M. Wilson AC. Mitochondrial DNA and human evolution. Nature 1987; 35: 31-6.

[21] Eaton SB, Konner M. Palaeolithic nutrition: a consideration of its nature and current implications. N Engl J Med 1985; 312(5): 283-9.

[22] Gilad Y, Oshlack A, Smyth GK, Speed TP, White KP. Expression profiling in primates reveals a rapid evolution of transcription factors. Nature 2006; 440: 242-5.

[23] Eaton SB. The ancestral human diet. What was it and should it be a paradigm for contemporary nutrition? Proc Nutr Soc 2006; 71: $1-7$.

[24] Emken EA, Adlof RO, Rakoff H, Rohwedder WK. Metabolism of deuterium-labelled linolenic, linoleic, oleic, stearic, and palmitic acid in human subjects. In: Baille TA, Jones JR, Eds. Synthesis and application of istopically labelled compounds. Amsterdam: Elsevier Science Publisher 1989; pp. 713-6.

[25] De Gómez Dumm IN, Brenner RR. Oxidative desaturation of alpha- linolenic, linoleic and stearic acids by human liver microsomes. Lipids 1975; 10: 315-7.

[26] Fedacko J, Vargova V, Singh RB, et al. (2011). Development of a verbal autopsy questionnaire to assess the association of dietary patterns with causes of death among urban decedents in North India: Dietary intakes and deaths study (DIADS). Open Nutr J 2011; (in press).

[27] Marx F. Corpus Medicorum Latinorum Editum Consilio et Auctoritate Instituti Puschmanniani Lipsiensis: Vol. I A. Cornelii Celsi Quae Supersunt Recensuit Fridericus Marx (Leipzig, Teubner, pp. CXIV + 484), 1915.

[28] Crum EL. Diet in ancient medical practice as shown by celsus in his de medicina. Classical Wkly 1932; 25(20):153-9.

[29] Halberg F, Cornélissen G, Schwartzkopff O, Holley D. Scope of a Chronoastrobiology Research Initiative. Available at: http:// cyclesresearchinstitute.org/cycles-health/health.shtml [Accessed June $\left.25^{\text {th }} 2011\right], 1999$.

[30] Halberg F, Carandente F, Cornélissen G, Katinas GS. Glossary of chronobiology. Chronobiologia 1977; 4(1): 1-189.

[31] Halberg F, Cornélissen G, Halberg E, et al. Toward chronobiologic optimization of nutrition for cancer treatment and broad disease prevention. Keynote address in: The Role of Nutrients in Cancer 
Treatment, Report of the 9th Ross Conference on Medical Research, Roche A.F. (ed.), pp. 2-9.Ross Laboratories, Columbus, OH, 1991.

[32] Halberg F, Cornélissen G, Shemerovsky C. From Pavlov's time coding and conditioned reflexes to a chronophysiology of human nutrition. Rom J Physiol 1995; 32: 97-106.

[33] Halberg F, Haus E, Cornélissen G. From biologic rhythms to chronomes relevant for nutrition. In: Marriott BM, Ed. Not eating enough: overcoming underconsumption of military operational rations. Washington D.C.: National Academy Press 1995; pp. 361-72.

[34] Halberg F, Cornélissen G, Shemerovsky KA, Ovsyannikov VI. From Pavlov's recording of time and conditioned reflexes to human nutrition chronophysiology. Invited lecture at symposium on "The Physiology of Digestion". Bull Russ Acad Med Sci 1996; 50: 47-51.

[35] Halberg F, Cornélissen G, Schwartzkopff O. Ambulatory blood pressure monitoring. In: Pella D, Singh RB, Chiang CE, Kong CW, Rastogi SS, Eds. International college of nutrition \& international college of cardiology. How to reverse the risk of heart attack, hypertension and diabetes. $2^{\text {nd }}$ ed. Moradabad: MYODEA 2005; pp. 41-52.

[36] Trout DL, King SA, Bernstein PA, Halberg F, Cornélissen G. Circadian variation in the gastric-emptying response to eating in rats previously fed once or twice daily. Chronobiology Int 1991; 8: $14-24$.

[37] Singh RB, Pella D, Chopra R, Cornélissen G, Halberg F. Overview of ubiquinone, in memory of a champion, Dr Emile G. Bliznakov. J Nutritional Environmental Med 2003; 13: 211-4.

[38] Cornélissen G, Halberg F. Foreword. In: Pella D, Singh RB, Chiang CE, Kong CW, Rastogi SS, Eds. International college of nutrition \& international college of cardiology. How to reverse the risk of heart attack, hypertension and diabetes. $2^{\text {nd }}$ ed. Moradabad: MYODEA 2005; pp. 7-10.

[39] Kaiser H, Cornélissen G, Halberg F. Paleochronobiology: circadian rhythms, gauges of adaptive Darwinian evolution; about 7-day (circaseptan) rhythms, gauges of integrative internal evolution. Prog Clin Biol Res 1990; 341B: 755-62.

[40] Halberg F, Cornélissen G, Sothern R, et al. International geographic studies of oncological interest on chronobiological variables. In: Kaiser Hans E, Ed. Neoplasms - Comparative pathology of growth in animals, plants and man. Baltimore: Williams \& Wilkins Co. 1981; pp. 553-96.

[41] Cornélissen G, Halberg F, Schwartzkopff O, et al. Editor's foreword: What Gesell wished, Hellbrügge accomplished: Chronomics of child development. Neuroendocrinol Lett 2003; 24(Suppl. 1): 14-24.

[42] Halberg F, Cornélissen G, Wilson D, et al. Chronobiology and chronomics: detecting and applying the cycles of nature. Biologist 2009; 56(4): 209-14

[43] Halberg F, Nelson W, Cornélissen G, Haus E, Scheving LE, Good RA. On methods for testing and achieving cancer chronotherapy. Cancer Treat Rep 1979; 63: 1428-30.

[44] Cornélissen G, Halberg E, Long HJ III, et al. Toward a chronotherapy of ovarian cancer with taxol. Part I: Basic background. Chronobiologia 1991; 18: 153-66.

[45] Shinagawa M, Kubo Y, Otsuka K, Ohkawa S, Cornélissen G, Halberg F. Impact of circadian amplitude and chronotherapy: relevance to prevention and treatment of stroke. Biomed Pharmacother 2001; 55: 125-32.

[46] Siegelova J, Fiser B, Dusek J, et al. Chronotherapy: rate-pressure produce in essential hypertension. In: Halberg F, Kenner $T$, Siegelova J, Eds. Proceedings, Symposium, chronobiological analysis in pathophysiology of cardiovascular system. Brno: Masaryk University 2003; pp. 118-21.

[47] Wang Z, Chen LG, Wan CM, Qu Y, Cornélissen G, Halberg F. In vitro circadian ANP secretion by gene transferring cells encapsulated in polycaprolactone tubes: gene chronotherapy. Peptides 2004; 25: 1259-67.

[48] Schwartzkopff O, Cornélissen G, Otsuka K, Halberg F. India revisited: a new hospital and center culminating multidecadal cooperation: From cancer chronotherapy to routine cardiovascular chronotheranostics and further joint Indian-US and international BIOCOS research. Biomed Pharmacother 2005; 59(Suppl. 1): S123-31.
[49] Cornélissen G, Delcourt A, Toussaint G, et al. Opportunity of detecting pre-hypertension: worldwide data on blood pressure overswinging. Biomed Pharmacother 2005; 59(Suppl. 1): S152-7.

[50] Halberg F, Cornélissen G. Chronobiology: rhythms, clocks, chaos, aging, and other trends. In: Maddox GL, Editor-in-chief. The encyclopedia of aging. $3^{\text {rd }}$ ed. New York: Springer 2001; pp. 196-201.

[51] Halberg F. Some aspects of the chronobiology of nutrition: more work is needed on 'when to eat'. J Nutr 1989; 119: 333-43.

[52] Chossat C. Recherches experimentales sur l'inanition. Mem Acad Roy Sci 1843; 8: 438.

[53] Forsgren E. Zur Kenntnis der Histologie der Leber zellen und der Gallensekretion. Anat Anz 1918; 51: 309-14.

[54] Forsgren E. On the relationship between the formation of bile and glycogen in the liver of the rabbit. Scand Arch Physiol 1928; 53: 137-51.

[55] Acren G, Wilander O, Jorfes E. Cyclic changes in the glycogen content of the liver and the muscles of rats and mice. Their bearing upon the sensitivity of the animals to insulin and their influence on the urinary output of nitrogen. Biochem J 1930; 25: 777-85.

[56] Higgins GM, Berkson J, Flock E. The diurnal cycle in the liver. 1. Periodicity of the cycle with analysis of chemical constituents involved. Am J Physiol 1932; 102: 673-82.

[57] Higgins GM, Berkson J, Flock E. The diumal cycle in the liver of the white rat: II. Food, a factor in its determination. Am J Physiol 1933; 105: 177-86.

[58] Haus E, Halberg F. Persisting circadian rhythm in hepatic glycogen of mice during inanition and dehydration. Experientia (Basel) 1966; $22: 113-4$.

[59] Halberg F, Visscher MB. A difference between the effects of dietary calorie restriction on the estrous cycle and on the 24-hour adrenal cortical cycle in rodents. Endocrinology 1952; 51: 329-35.

[60] Halberg F, Visscher MB, Bittner JJ. Eosinophil rhythm in mice: range of occurrence; effects of illumination, feeding and adrenalectomy. Am J Physiol 1953; 174: 109-22.

[61] Graeber RC, Gatty R, Halberg F, Levine H. Human eating behavior: preferences, consumption patterns, and biorhythms. U.S. Army Technical Report, NATICK/TR-78/023, 1978; p. 287.

[62] Nelson W, Halberg F. Schedule-shifts, circadian rhythms and lifespan of freely-feeding and meal-fed mice. Physiol Behav 1986; 38: 781-8.

[63] Halberg F, Cornélissen G, Katinas G, Hillman D, Schwartzkopff O. Season's appreciations 2000: chronomics complement, among many other fields, genomics and proteomics. Neuroendocrinol Lett 2001; 22: 53-73.

[64] Halberg F, Cornélissen G, Otsuka K, Schwartzkopff O, Halberg J, Bakken EE. Chronomics. Biomed Pharmacother 2001; 55: 1-39.

[65] Halberg F, Cornélissen G, Schack B, et al. Blood pressure selfsurveillance for health also reflects 1.3-year Richardson solar wind variation: spin-off from chronomics. Biomed Pharmacother 2003; 57: $58 \mathrm{~s}-76$

[66] Watanabe Y, Hillman DC, Otsuka K, et al. Cross-spectral coherence between geomagnetic disturbance and human cardiovascular variables at non-societal frequencies. Chronobiologia 1991; 21: 265-72.

[67] Breus TK, Halberg F, Cornélissen G. Influence of solar activity on the physiological rhythms of biological systems. Biofizika (Russian) 1995; 40(4): 737-48.

[68] Breus TK, Cornélissen G, Halberg F, Levitin AD. Temporal associations of life with solar and geophysical activity. Ann Geophys 1995; 13: 1211-22.

[69] Mikulecky M, Ed. The moon and living matter. Kosice, Slovakia, September 23-25, Bratislava: Slovak Medical Society 1993.

[70] Mikulecky M, Ed. Sun, moon and living matter. Bratislava, Slovakia, June 28-July 1, 1994. Bratislava: Slovak Medical Society 1994.

[71] Mikulecky M, Ed. Chronobiology and its roots in the cosmos. High Tatras, Slovakia, September 2-6, 1997. Bratislava: Slovak Medical Society 1997.

[72] Otsuka K. Proceedings, 1st International Symposium, Workshop on Chronoastrobiology and Chronotherapy (Satellite Symposium, 7th Annual Meeting, Japanese Society for Chronobiology), Kudan, Chiyodaku, Tokyo, 11 Nov. 2000.

[73] Voltaire F-MA. Candide. Bair L. Ed. New York: Bantam Dell 1959. 
[74] Weiss KM, Dunsworth HM. Dr. Panglos's nose in evolution, cause, correlation, and effect are not always identical. Evolutionary Anthropology 2011; 20: 3-8.

[75] Halberg F, Cornélissen G, Katinas GS, Watanabe Y, Siegelová J. Cosmic inheritance rules: implications for health care and science. Scr Med 2010; 83(1): 5-32.

[76] Sagan C, Mullen G. Earth and Mars: Evolution of atmospheres and surface temperatures. Science 1972; 177: 52-6.

[77] Kasting JF, Howard MT. Atmospheric composition and climate on the early Earth. Philos Trans R Soc B 2006; 361: 1733-42.

[78] Ram M. Stolz M, Koenig G. Eleven year cycle of dust concentration variability observed in the dust profile of the GISP2 ice core from Central Greenland: possible solar connection. Geophys Res Lett 1997; 24: 2359-62.

[79] Tkachuck RD. The little ice age. Origins 1983; 10(2): 51-65.

[80] Schwabe H. Excerpts from solar observations during 184. Astronomische Nachrichten 1843; 20(495): 234-5.

[81] Hale GE. On the probable existence of a magnetic field in sunspots. Astrophys J 1908; 28: 315-43.

[82] Hale GE, Ellerman F, Nicholson SB, Joy AH. The magnetic polarity of sun-spots. Astrophysical J 1919; 49: 153-78.

[83] Arrhenius S. Worlds in the making: The evolution of the universe. New York: Harper \& Row 1908.

[84] Hourani G. The life and thought of Ibn Rushd. Cairo, Egypt: American University Press 1947.

[85] Atkinson N. Shedding new light on the cosmic dark ages. News and Events. University of Cambridge Press Release. $5^{\text {th }}$ January 2011, Available at: http://www.admin.cam.ac.uk/news/dp/2011010502 [Accessed 27th June 2011].

[86] Turtoi C, Cornélissen G, Wilson D, Halberg F. About 21-year hale cyclic signature in agriculture complement those in biomedicine. Biomed Pharmacother 2004; 58(Suppl. 1): S12-4.

[87] Halberg F, Cornélissen G, Singh RB, Schwartzkopff O. The challenge and opportunity of blood pressure chronomics in India. In: Rao GHR, Ed. Thanikachalam S, Assoc. Ed. Coronary artery disease: risk promoters, pathophysiology and prevention. New Delhi: Jaypee 2005; pp. 353-67.

[88] Cornélissen G, Halberg F, Sothern RB, Hillman D. Parasemiannuality: selectively environmentally congruent biotic cis-halfyear unmasked with neighboring spectral components. In: Halberg F, Kenner T, Fiser B, Siegelova J, Eds. Proceedings, Noninvasive methods in cardiology. Brno; Czech Republic: National center of Nursing and Paramedical fields in corporation with the Masaryle University 2009; pp. 112-40.

[89] Hunter MN. A theory concerning the geomagnetic-solar influence on weather and climate. J Geophys Res 1960; 65: 2499.

[90] Bucha V. Mechanism of the relations between the changes of the geomagnetic field, solar corpuscular radiation, atmospheric circulation and climate. J Geomagn Geoelectr 1980; 32: 217-64.

[91] Bucha V. Temperature changes in relation to geomagnetic activity. In: Ruzickova E, Zeman A, Mirecki J, Eds. Application of direct and indirect data for the reconstruction of climate during the last two millennia. Prague: Academy of Sciences of Czech Republic, Geological Institute 1993.

[92] Labitzke K, van Loon H. Association between the 11-year solar cycle and the atmosphere. Part V: Summer. J Climate 1992; 5: 240-51.

[93] Labitzke K, van Loon H. Some recent studies of probable connection between solar and atmospheric variability. Ann Geophysicae 1992; 11: 1084-94.

[94] Friis-Christensen E, Lassen K. The length of the solar cycle: an indicator of solar activity closely associated with the terrestrial climate. Science 1991; 254: 698-700.

[95] Grafe A, Heider F. Geomagnetic activity and global tropospheric temperature variations. Geophys Process Biosph 2011; in Press.

[96] Tanner M. Directorate, Swiss Tropical and Public Health Institute, Basel- lecture given at the Wolfson Institute, Queen's Campus, Durham University, Stockton-on-Tees, June $16^{\text {th }}, 2011$.

[97] King James. The Holy Bible. Ecclesiastes 3:1-8. London, HarperCollins, 1611.

[98] Chavarria F. Civilisation diseases, time and space. In: Krieps R, Ed. Environment and health: a holistic approach. Aldershot: Gower Publishing Company 1989.

[99] Hathaway DH, Wilson RM. Geomagnetic activity indicates large amplitude for sunspot cycle 24. Geophys Res Lett 2006; 33: L18101.

[100] Cornélissen G, Halberg F, Zeman M, et al. Towards a chronome (time structure) of melatonin. In: Pandi-Perumal SR, Cardinali DP,
Eds. Melatonin: From molecules to therapy.. Hauppauge, NY, USA: Nova Science Publishers Inc. 2007.

[101] Parker EN. Dynamics of the interplanetary gas and magnetic fields. Astrophys J 1958; 128: 664.

[102] Wilson DW. Health of inner cities and urban areas: concepts, perspectives, reality and research. Stat 1990; 39: 111-3.

[103] Dawkins R. The selfish gene. $2^{\text {nd }}$ ed. UK: Oxford University Press 1989; p. 192.

[104] Blackmore S. Evolution and memes: The human brain as a selective imitation device. Cybernet Syst 2001; 32: 225-55.

[105] Vernadsky W. The biosphere and the noosphere. Am Sci 1915; 33(1): 8-9.

[106] Cornélissen G. Celebrating Franz Halberg's 90th birthday. J Appl Biomed 2010; 8: 117-8.

[107] Russell J. The awakening Earth. London: Ark 1981.

[108] Lovelock J. The ages of Gaia: a biography of our living Earth. New York: WW Norton \& Co. 1995.

[109] Gurpide E, Mann J. Estimation of secretory rates of hormones from the specific activities of metabolites which have multiple secreted precursors. Bull Math Biol 1965; 27(4): 389-406.

[110] Berman M. Compartmental analysis in kinetics. In: Stacy R, Warman B, Eds. Computers in biomedical research Vol. II, New York: Academic Press 1965

[111] Mayakawa MT, DiStephano JJ III, Swerdloff RS. A dynamic system model of testosterone transport and metabolism in normal man. Ann Biomed Eng 1974; 2; 307-20.

[112] Halberg F, Cornélissen G, Conti A, et al. The pineal gland and chronobiologic history: mind and spirit as feedsidewards in time structures for prehabilitation. In: Bartsch C, Bartsch H, Blask DE, Cardinali DP, Hrushesky WJM, Mecke W, Eds. The pineal gland and cancer: neuroimmunoendocrine mechanisms in malignancy. Heidelberg: Springer 2001; pp. 66-116.

[113] Drossman DA, Corazziari E, Delvaux M, et al Eds. Rome III: The functional gastrointestinal disorders, $3^{\text {rd }}$ ed. McLean: Degnon Associates, Inc., Virginia 2006; pp. 963-90.

[114] Zeman M, Cornélissen G, Balazova K, et al. Circadian rhythm of melatonin in rat duodenum. In: Cornélissen G, Kenner R, Fiser B, Siegelova J, Eds. Proceedings, Symposium: Chronobiology in Medicine. Brno: Masaryk University 2004; pp. 95-7.

[115] Weydahl A, Sothern RB, Cornélissen G, Wattenberg L. Geomagnetic activity influences the melatonin secretion at latitude $70^{\circ}$ N. Biomed Pharmacother 2001; 55: 57-62.

[116] Wilson DW, Gaskell SJ, Kemp KW, Eds. Proceedings of 8th tenovus workshop: quality control in clinical endocrinology. Cardiff: Alpha Omega Pub 1981.

[117] Freedman B. Equipoise and the ethics of clinical research. N Engl J Med 1987; 317 (3): 141-5.

[118] Halberg F, Cornélissen G, Grambsch P, et al. Personalized chronobiologic cybercare; other chronomics' progress by transdisciplinary cycles' congruences. J Appl Biomed 2011; 9: 1-34.

[119] Tarquini B, Tarquini R, Perfetto F, Tapparini L, Lombardi A, Pignone A. Chronobiology in epidemiology and preventive medicine. Ann $1^{\text {st }}$ Super Sanità 1993; 29: 559-67.

[120] Wilson DW, Gaskell SJ, Fahmy DR., et al. Development of statistical and analytical techniques for use in national quality control schemes for steroid hormones. In: Bizollon A, Ed. "Radioimmunology 1979". Amsterdam: Elsevier/North-Holland Biomedical Press 1979, pp. 281-94.

[121] Wilson DW, Nix ABJ, Rowlands RJ, Kemp KW, Griffiths K. Analytical performance characteristics and chronobiological considerations in quality control. In: Wilson DW, Gaskell SJ, Kemp KW, Eds. Proc. $8^{\text {th }}$ tenovus workshop: quality control in clinical endocrinologY. Cardiff: Alpha Omega Pub 1981; pp. 5-18.

[122] Wilson D, Sarfaty G, Clarris B, Douglas M, Crawshaw K. The prediction of standard curves and errors for the assay of estradiol by competitive protein binding. Steroids 1971; 18: 77-90.

[123] Nix ABJ, Wilson DW. Assay detection limits: concept, definition and estimation. Eur J Clin Pharmacol 1990; 39: 203-6.

[124] Halberg F, Lee J-K, Nelson W. Time-qualified reference intervals chronodesms. Experientia 1978; 34: 713-6.

[125] Foster M. Claude Bernard. New York: Longmans, Green \& Co. 1899.

[126] Halberg F. Claude Bernard, Referring to an 'Extreme Variability of the Internal Milieu' In: Grande F, Visscher MB, Eds. Claude bernard and experimental medicine. Cambridge, Massachusetts: Schenkman Publ Co. 1967; p. 193. 
[127] Halberg F, Lauro R, Carandente F. Autorhythmometry leads from single-sample medical check-ups toward a health science of time series. La Ricerca Clin Lab 1976; 6: 207-50.

[128] Halberg F. Temporal coordination of physiologic function. Cold Spr Harb Symp Quant Biol 1960; 25: 289-310.

[129] Anon. World Health Organization. Constitution of the World Health Organization - Basic Documents, $45^{\text {th }}$ ed. Supplement, October, 2006.

[130] West JB. Physiological basis of medical practice. $12^{\text {th }}$ ed. Baltimore: Williams and Wilkins 1989.

[131] Kowalewski K. Urinary neutral 17-ketosteroids in the aged. J Gerontology 1950; 5(3): 222-6.

[132] Bartter FC, Delea CS, Halberg F. A map of blood and urinary changes related to circadian variations in adrenal cortical function in normal subjects. Ann NY Acad Sci 1962; 98: 969-83.

[133] Halberg F, Hamburger C. 17-ketosteroid and volume of human urine. Weekly and other changes with low frequency. Minn Med 1961; 47: 916-25.

[134] Menini E, Norymberski JK. An approach to the systematic analysis of urinary steroids. Biochem J 1965; 95: 1-16.

[135] Sarfaty G, Tallis M. Aspects of the reliability of a urinary 17hydroxycorticosteroid Assay. J Clin Endocrinol Metab1970; 31(1): 52-9.

[136] Dawes C. Circadian rhythms in the flow rate and composition of unstimulated and stimulated human submandibular saliva. J Physiol 1975; 244: 535-48.

[137] Leeson CR. Structure of salivary glands. In: Code CF, Eds. Handbook of physiology. Vol. 2. Baltimore: Williams and Wilkins, 1967; pp. 463-95.

[138] Laine M, Ojanotko-Harri A. Progesterone metabolism by major salivary glands of rat I. Submandibular and sublingual glands. J Steroid Biochem 1990; 35: 723-8.

[139] Wilson DW, Walker RF, Griffiths K. Saliva as a medium for chronobiological studies: its particular potential to steroid endocrinology. Ann Ist Super Sanità 1993; 29(4): 607-11.

[140] Read GF, Walker R, Wilson DW, Griffiths K. Steroid analysis in saliva for the assessment of endocrine function. In: Castagnetta L, d'Aquino S, Labrie F, Bradlow HL, Eds. Steroid formation, degradation, and action in peripheral tissues. Vol. 595, New York: New York Academy of Sciences 1990; pp. 260-74.

[141] Walker RF, Wilson DW, Read GF, Riad-Fahmy D. Assessment of testicular function by the radioimmunoassay of testosterone in saliva. Int J Androl 1980; 3: 105-20.

[142] Read GF, Wilson DW, Campbell FC, Holliday HW, Blamey RW, Griffiths K. Salivary cortisol and dehydroepiandrosterone sulphate levels in postmenopausal women with primary breast cancer. Eur J Cancer Clin Oncol 1983; 19: 477-83.

[143] Spaan M, Porola P, Laine M, Rozman B, Azuma M, Konttinen YT. Healthy human salivary glands contain a DHEA-sulphate processing intracrine machinery, which is deranged in primary Sjögren's syndrome. J Cell Mol Med 2009; 13(7): 1261-70.

[144] Vining RF, McGinley RA. The measurement of hormones in saliva: possibilities and pitfalls. J Steroid Biochem 1987; 27: 81-94.

[145] Campbell IT, Walker RF, Riad-Fahmy D, Wilson DW, Griffiths K. Circadian rhythms of testosterone and cortisol in saliva: effects of activity-phase shifts and continuous daylight. Chronobiologia 1982; IX: 389-96.

[146] Lipson S, Ellison P. Development of protocols for the application of salivary steroid analysis to field conditions. Am J Hum Biol 1989; 1: 249-55.

[147] Dabbs JM. Salivary testosterone measurements: Collecting, storing and mailing saliva samples. Physiol Behav 1990; 49: 815-7.

[148] Ahn RS, Lee YJ, Choi JY, Kwon HB, Chun SI. Salivary cortisol and DHEA levels in the population: age-related differences, diurnal rhythm, and correlations with serum levels. YMJ 2007; 48(3): 379-88

[149] Blom T, Ojanotko-Harri A, Laine M, Huhtaniemi I. Metabolism of progesterone and testosterone in human parotid and submandibular salivary glands in vitro. J Steroid Biochem Mol Biol 1993; 44(1): 69-76.

[150] Gallagher P, Leitch MM , Massey AE, McAllister-Williams RH, Young AH. Assessing cortisol and dehydroepiandrosterone (DHEA) in: effects of collection method. J Psychopharmacol 2006; 20(5): 643-9.

[151] Herbst AL, Ulfelder H, Poskanzer DC. Adenoma of the vagina. Association of maternal stilboestrol therapy with tumor appearance in young women. N Engl J Med 1971; 284: 878-81.
[152] Li S, Hursting SD, Davis BJ, McLachlan JA, Barrett JC. Environmental exposure, DNA methylation, and gene regulation: lessons from diethylstilbesterol-induced cancers. Ann NY Acad Sci 2003; 983: 161-9.

[153] Francis SJ, Walker RF, Riad-Fahmy D, Hughes D, Murphy JF, Gray OP. Assessment of adrenalcortical activity in term newborn infants using salivary cortisol determinations. J Pedeatr 1987; 111: 129-33.

[154] Ellison PT, Peacock NR, Lager C. Salivary progesterone and luteal function in two low-fertility populations in Northeast Zaire. Hum Biol 1986; 58(4): 473-83.

[155] Nunez-de la Mora A, Bentley GR. Changes in risk factors for breast cancer in migrant women: an inter-generational comparison among Bangladeshis in the UK. In: Panter-Brick C, Fuentes A, Eds. Health, risk and adversity: a contextual view. New York: Berghahn Press 2008; pp. 129-49.

[156] Nunez-de la Mora A, Chatterton RT, Bentley GR. Changes in risk factors for breast cancer in migrant women: an inter-generational comparison among Bangladeshis in the UK. In: Panter-Brick C, Fuentes A, Eds. Health, risk and adversity: a contextual view. New York: Berghahn Press 2008; pp. 129-49.

[157] Lipson SF, Ellison PT. Comparison of salivary steroid profiles in naturally occurring conception and non-conception cycles. Hum Reprod 1996; 11: 2090-6.

[158] Finlay EMH, Wilson DW, Adlercreutz H, Griffiths K. The identification and measurement of 'phyto-oestrogens' in human saliva, plasma, breast aspirate or cyst fluid, and prostatic fluid using gas chromatography-mass spectrometry. J Endocrinol 1991; 129: 49.

[159] Ueno-Towatari T, Norimatsu K, Blazejczyk K, Tokura H, Morita T. Seasonal variations of melatonin secretion in young females under natural and artificial light conditions in Fukuoka, Japan. JPA 2007; 26(2): 209-15

[160] Choosong T, Arporn S, Chaikittiporn C. A study of melatonin levels and stress in female shift workers. Southeast Asian J Trop Med Public Health 2006; 37(5): 1048-53.

[161] Eriksson K, Ostin A, Levin JO. Quantification of melatonin in human saliva by liquid chromatography-tandem mass spectrometry using stable isotope dilution. J Chromatogr B, Anal Technol Biomed Life Sci 2003; 794(1): 115-23.

[162] Grundy A, Sanchez M, Richardson H, Tranmer J, Borugian M, Graham $\mathrm{CH}$, Aronson KJ. Light intensity exposure, sleep duration, physical activity, and biomarkers of melatonin among rotating shift nurses. Chronobiol Int 2009; 26(7): 1443-61.

[163] Birchler-Pedross A, Schröder CM, Münch M, et al. Subjective well-being is modulated by circadian phase, sleep pressure, age, and gender. J Biol Rhythms 2009; 24(3): 232-42.

[164] Bagci S, Mueller A, Reinsberg J, Heep A, Bartmann P, Franz AR. Saliva as a valid alternative in monitoring melatonin concentrations in newborn infants. Early Hum Dev 2009; 85(9): 595-8.

[165] Konturek SJ, Pepara J, Zabielski K, Konturek PC, Pawlik T, Szlachcic AA. Brain-gut axis in pancreatic secretion and appetite control. J Physiol Pharmacol 2003; 54: 293-317.

[166] Skene DJ, Arendt J. Circadian rhythm sleep disorders in the blind and their treatment with melatonin. Sleep Med 2007; 8(6): 651-5.

[167] Zhou JN, Liu RY, van Heerikhuize J, Hofman MA, Swaab DF. Alterations in the circadian rhythm of salivary melatonin begin during middle-age. J Pineal Res 2003; 34(1): 11-6.

[168] Zeiger E, Farquhar GD, Cowan IR. Stomatal function. California, USA: Stanford University Press, 1987

[169] Spence RD. The problem of variability in stomatal responses, particularly aperture variance, to environmental and experimental conditions. New Phytol 1987; 103: 303-15.

[170] Barthlott W, Neinhuis C. Purity of the sacred lotus, or escape from contamination in biological surfaces. Planta 1997; 202: 1-8

[171] Haus E. Chronobiology in the endocrine system. Adv Drug Deliv Rev 2007; 59: 985-1014.

[172] Hirayama T. A large scale cohort study on cancer risk by diet with special reference to the risk reducing effects of green-yellow vegetable consumption. In: Hayashi Y, Minako N, Sugimura T, Takayama S, Tomatis L, Wattenberg LW, Eds. Logan, Tokyo: Japanese Societies Press 1986.

[173] Doll R, Peto R. The causes of cancer: quantitative estimates of avoidable risks of cancer in the United States today. J Natl Cancer Inst 1981; 66: 1191-308. 
[174] Miller AB, Berriono F, Hill M, Pietinen P, Riboli E, Wahrendorf J. Diet in the aetiology of cancer: a review. Eur J Cancer 1994; 30A: 207-20.

[175] Dhom G. Epidemiology of hormone-dependent tumours. In: Voigt KD, Knabbe C, Eds. Endocrine dependent tumours. New York: Raven Press 1991; pp. 1-42.

[176] Cornélissen G, Halberg F, Otsuka K, et al. Iatrogenic excessive blood pressure variability (CHAT): implications for chronotherapy. Scripta Medica (Brno) 2003; 76: 275-8

[177] Watson R, Wright CJ, McBurney T, Taylor AJ, Linforth RST. Influence of harvest date and light integral on the development of strawberry flavour compounds. J Exp Bot 2002; 53: 2121-9.

[178] Cordenunsi B, Genovese M, Nascimento J, Hassimotto N, Dos Santos R, Lajolo F. Effects of temperature on the chemical composition and antioxidant activity of three strawberry cultivars. Food Chem 2005; 91: 113-21.

[179] Davik J, Bakken AK, Holte K, Blomhoff R. Effects of genotype and environment on total anti-oxidant capacity and the content of sugars and acids in strawberries (Fragaria $\times$ ananassa Duch.). J Hortic Sci Biotech 2006; 81(6): 1057-63.

[180] Tressl R, Drawert F, Heimann W. Gaschromatographischmassenspektroetrische Bestandsaufnahme von ErdbeerAromastoffen. Zeitschrift fuer Naturforschung. Teil B 1969; 24: 1201-2.

[181] Manning K. Soft fruits. In: Seymour GB, Taylor JE, Tucker GA, Eds. Biochemistry of fruit ripening. London: Chapman \& Hall 1996; pp. 347-73.

[182] Cordenunsi BR, Nascimento JRO, Lajolo FM. Physico-chemical changes related to quality of five strawberry fruit cultivars during cool-storage. Food Chem 2003; 83: 167-73.
[183] Herbert RB. The biosynthesis of secondary metabolites. $2^{\text {nd }}$ ed. London: Chapman and Hall 1989.

[184] Grun IU, Koushik A, Li C, et al. Changes in the profile of genistein, daidzein and their conjugates during thermal processing of tofu. J Agric Food Chem 2001; 49: 2839-43.

[185] Griffiths K, Adlercreutz H, Boyle P, Denis L, Nicholson RI, Morton MS. Nutrition and cancer. Oxford: Isis Medical Media Ltd 1996.

[186] Yang C, Hong J-Y, Wang Z-Y. Inhibition of nitrosamine-induced tumourigenesis by diallyl sulphide and tea. In: Waldron $\mathrm{KW}$, Johnson IT, Fenwick GR, Eds. Food and cancer prevention: chemical and biological aspects. Cambridge: Royal Society of Chemistry 1993; pp. 247-52.

[187] Sumiyoshi H, Wargovich MJ. Chemoprevention of 1,2dimethylhydrazine-induced colon cancer in mice by naturally occurring sulphur compounds. Cancer Res 1990; 50: 5084-7.

[188] Liakopoulou-Kyriakides M. Relation between the structure of alliin analogues and their inhibitory effect on platelet aggregation. Phytochemistry 1985; 24: 1593-4

[189] Valsta LM, Kilkkinen A, Mazur W, et al. Phyto-oestrogen database of foods and average intake in Finland. Br J Nutr 2003; 89(Suppl.1): S31-8.

[190] Milder IE, Arts IC, van de Putte B, Venema DP, Hollman PC Lignan contents of Dutch plant foods: a database including lariciresinol, pinoresinol, secoisolariciresinol and matairesinol. Br J Nutr 2005; 93(3): 393-402.

[191] Higgins R. The Colossus of Rhodes. In: Clayton P, Price M, Eds. The seven wonders of the ancient world, New York: Routledge 1988; pp. 124-37.

\begin{tabular}{lll}
\hline Received: January 07, 2012 & Revised: January 25, 2012 Accepted: January 27, 2012
\end{tabular}

(C) Wilson et al.; Licensee Bentham Open.

This is an open access article licensed under the terms of the Creative Commons Attribution Non-Commercial License (http://creativecommons. org/licenses/ by-nc/3. 0/) which permits unrestricted, non-commercial use, distribution and reproduction in any medium, provided the work is properly cited. 